\title{
DOCUMENTO
}

\section{NOTÍCIA SUMÁRIA SOBRE AS INSTITUIÇÕES ESCOLARES DA SUÍÇA (1911)}

\author{
Short notice over school institutions in Switzerland (1911)
}

\author{
Carlos Manique da Silva \\ Instituto de Educação da Universidade de Lisboa, Portugal.
}

\section{$\cos 80$}

\section{Introdução}

Em 10 de junho de 1911, Boaventura José Dias Garção (1885-?), professor do ensino primário oficial em Borba, Alentejo, mas à data a residir na Suíça, mais precisamente na cidade de Berna, solicita nomeação para "qualquer das novas Escolas de ensino primário superior" (IAN/TT. Ministério da Instrução Pública, Cx. 82, Proc. 16) ${ }^{1}$, consignadas, acresce dizê-lo, na primeira reforma republicana do ensino infantil, primário e normal (decreto de 29 de março de 1911) ${ }^{2}$. A missiva foi enviada à Legação de Portugal na Suíça, sediada em Berna, que, por sua vez, a remeteu ao ministro do Interior, António José de Almeida, em 28 de junho do dito ano, indicando tratar-se de um pedido de um pensionista do Estado "que acaba de concluir distintissimamente o curso da Escola Normal de Berna" (Ibid.). O mais relevante é que esse mesmo requerimento chegou a Lisboa, ao gabinete de António José de Almeida, acompanhado de outros dois documentos solicitados a Boaventura Garção pelo responsável da Legação de Portugal na Suíça.

Trata-se, por um lado, de um parecer sobre a mencionada Reforma de 29 de março de 1911, precisamente decretada por António José de Almeida, que abordarei aqui tangencialmente, e, por outro lado, de uma Notícia sumária sobre as instituições escolares da Suiça, a qual será objeto de análise e de publicação na íntegra. Sabemos,

${ }^{1}$ Os documentos citados ao longo do presente artigo encontram-se no acervo do Instituto dos Arquivos Nacionais/Torre do Tombo, Ministério de Instrução Pública, Caixa 82, Processo 16. Optou-se por atualizar a grafia dos documentos.

${ }^{2}$ Em Portugal, talvez seja útil referi-lo, a implantação da República ocorreu em 5 de outubro de 1910. 
ainda, que os dois documentos foram escritos num lapso de tempo de 24 horas, a pedido então do representante da Legação de Portugal na Suíça com o "intuito de avaliar as suas [de Boaventura Garção] qualidades de inteligência e os seus conhecimentos pedagógicos" (Ibid.), sendo que a apreciação, por parte do mesmo representante, foi positiva.

Outras informações a respeito da permanência de Boaventura Garção no Cantão de Berna podem ser obtidas no parecer que emite sobre a Reforma de 1911; documento original com cinco páginas, assinado, não datado, mas elaborado num único dia entre 10 e 28 de junho do referido ano. Ora, nesse texto, o pensionista português refere que está em Berna há quatro anos, sabemo-lo com o propósito de estudar na Escola Normal, cujo curso, aliás, concluiu em $1^{\circ}$ de maio de 1911. Atendendo à cronologia, é muito provável que Boaventura Garção tenha sido um dos pensionistas portugueses que rumou ao estrangeiro ao abrigo do decreto de 29 de maio de 1907; diploma que abriu concurso de bolsas de estudo para visitas ou estágios em diversos países da Europa ${ }^{3}$. O caso presente, porém, concerne a uma estadia de longa duração.

Neste passo da narrativa afigura-se útil dizer, na linha, aliás, da argumentação de Eckhardt Füchs (2007), que o estudo de viagens e estadias no estrangeiro colhe especial sentido quando estão relacionadas com a difusão de novas ideias e métodos pedagógicos; o mesmo é dizer que devem ser compreendidas no quadro de redes educativas internacionais ou de influência transnacional (Mignot; Gondra, 2007). Percebemos, de resto, que as intenções do pensionista Boaventura Garção não se cingiam ao simples relato informativo sobre a organização dos estudos na Suíça. De facto, o seu propósito maior era o de contribuir para a melhoria da educação em Portugal, apropriando-se e pondo em circulação os modernos métodos pedagógicos. $E$ aqui o olhar comparativo e, em consequência, o tópico do atraso educacional eram inevitáveis, conforme fica patente numa passagem do parecer sobre a Reforma de 1911: "comparava diariamente essa excelente organização de ensino com o lamentável contraste em que se encontrava a nossa instrução primária e normal" (IAN/TT. Ministério da Instrução Pública, cx. 82, proc. 16). Do seu ponto de vista, e continuo a acompanhar o referido parecer, não havia razão para que em Portugal não se fizesse "o mesmo que [em] alguns países civilizados" (Ibid.). No seu espírito está, pois, presente a ideia de criar um sistema escolar comparável ao de alguns países europeus, em particular ao da Suíça ${ }^{4}$; tal preocupação reformista pauta, na verdade, a elaboração do parecer.

Para si, porém, a Reforma de 29 de março 1911 abria uma janela de oportunidade num país que implantara a República há muito pouco tempo. De facto, conforme manifestava, o diploma reformador era um "trabalho magistralmente elaborado, consciencioso, de superior critério e que revela profundos conhecimentos pedagógicos" (Ibid.). Todavia, pretendia ver nele algum aprofundamento, tomando a liberdade de apresentar a António José de Almeida um conjunto de sugestões. Nesse sentido, advoga que o ensino obrigatório só termine com a realização do exame complementar, e não o elementar; a ideia aqui presente é, de modo óbvio, a do prolongamento da escola primária; também, de certa maneira, a da democratização do ensino. Por outro lado,

\footnotetext{
${ }^{3}$ A respeito das viagens de alguns bolseiros portugueses, precisamente no âmbito do citado diploma, vejase, por exemplo, os estudos de Fernandes (1971) e de Pintassilgo (2007).

${ }^{4}$ Em 1904, o professor espanhol Martí Alpera utiliza uma frase muito elucidativa quando se reporta à Suíça, considerando-a "la Meca de la Pedagogía moderna" (apud Moreno-Martínez, 2007, p. 131). 
preconiza a substituição do ditado e das cópias no programa de língua portuguesa. Em alternativa surgiriam a composição obrigatória sobre assuntos de lições de coisas aprendidos na escola ou composições livres sobre assuntos da experiência das crianças.

Essa via, no seu entender, "seria a melhor forma de aproveitar bem a inteligência das crianças obrigando-as a pensar, a inventar e não a mecanizar o ensino" (Ibid.). É, assim, notória a reivindicação de uma escola adaptada aos alunos, dando particular atenção às suas necessidades intelectuais e aptidões especiais. Por antagónico que possa parecer, o autor faz também a apologia da escola graduada, cujo pressuposto é o de constituir classes supostamente o mais homogéneas possível, dando a conhecer de que forma nos estabelecimentos escolares suíços se fazia a divisão do trabalho docente: as professoras especializavam-se no $1^{\circ}$ e $2^{\circ}$ anos de escolaridade ao passo que os professores lecionavam unicamente $\circ 3^{\circ}, 4^{\circ}$ e $5^{\circ}$ anos de escolaridade. Sustenta, ainda, reportando-se ao contexto português, que nas escolas normais e nos liceus se deveria acabar com a prática de um ou dois alunos serem "chamados à lição como se fosse um exame ficando os outros alunos despreocupados" (Ibid.); revivescência clara do método ou modo individual.

Passemos agora a analisar, nas suas linhas de maior força e na sua estruturação, a Notícia sumária sobre as instituições escolares da Suíça. Trata-se de um documento original com 22 páginas, de igual modo redigido num único dia entre 10 e 28 de junho de 1911, não estando assinado por Boaventura Garção, mas sendo seguramente de sua lavra. Em primeiro lugar, e dada a extensão do texto, importa dizer que o autor teve pouco tempo para a sua redação. Notam-se, por isso, alguns desfasamentos no que concerne a cálculos: tal é o caso, por exemplo, do número de alunos nos cantões. É claro, por outro lado, e ainda numa apreciação muito geral, que o texto teve por suporte algumas fontes primárias. O registo é tendencialmente objetivo, embora, por vezes, sejam percetíveis juízos de valor.

A Notícia sumária sobre as instituições escolares da Suíça dá-nos uma panorâmica bastante abrangente sobre o sistema educativo desse país. Tal facto decorre, em boa medida, da própria estrutura do documento. Na verdade, o autor opta por dividi-lo em duas grandes seções. Isto é, num momento introdutório, por assim dizer, carateriza o sistema escolar suíço numa perspetiva o mais lata possível, reportando-se aos vários cantões. Posteriormente dedica especial atenção, como seria, de resto, expectável, ao Cantão de Berna.

Ora, Boaventura Garção começa por explicar o regime de administração escolar dos cantões, sublinhando os limites da intervenção do Estado no governo dos assuntos educativos. De modo muito significativo, a Notícia abre com a seguinte frase: "A Suíça não tem ministério da instrução pública" (Ibid.). ${ }^{5}$. Destaca depois a diversidade dos cantões, espelhada nos respetivos normativos, bem como o facto de cada uma dessas pequeninas repúblicas se encontrar, de modo diferente, na vanguarda pedagógica - aqui a distinção que faz é, no essencial, entre Suíça alemã e Suiça francesa. Explica, ainda, a organização dos vários níveis de ensino, das escolas infantis ao ensino superior, mobilizando, amiúde, dados estatísticos: número de alunos, orçamentos. Refere-se, de igual modo, ao ensino profissional, à formação do pessoal docente e às escolas

\footnotetext{
${ }^{5}$ Em Portugal, talvez seja importante contextualizar, o Ministério da Instrução Pública foi definitivamente criado em 1913, depois de ter tido existência efémera no século 19 (1870 e 1890-1892). 
destinadas aos alunos com algum tipo de deficiência - institutos para surdos-mudos, escolas e classes para anormais.

Na segunda parte da Notícia, exclusivamente dedicada às instituições escolares do Cantão de Berna, a narrativa é mais apurada e pormenorizada, naturalmente resultante de um conhecimento mais aprofundado das realidades educativas. Na verdade, mesmo continuando a seguir o esquema de descrição adotado na primeira parte do documento, ou seja, a ordem sequencial dos vários níveis de ensino, o autor acaba, porém, por se deter em alguns aspetos que considera relevantes. É exemplo a atenção prestada à escolaridade obrigatória, sendo que Boaventura Garção descreve com minúcia o número de horas anuais que devem ser ministradas em cada grau do ensino primário - o tempo de duração da escolaridade é de 8 ou 9 anos, consoante as comunas. Esta tónica tem, obviamente, que ver com a defesa de uma integração escolar extensiva ao ensino primário superior, prevista na legislação portuguesa de 1911, justamente no citado decreto de 29 de março, mas que só viria a ser concretizada em 1919.

Por outro lado, a Notícia carateriza com rigor o ensino secundário, permitindo dessa forma compreender as caraterísticas e os objetivos das diversas vias estabelecidas. Uma situação muito diferente da registada em Portugal, onde era pouco diversificada a oferta formativa no ensino secundário. A ideia era a de estabelecer confronto no sentido de dar maior visibilidade àquilo que era considerado avançado em termos pedagógicos. Mas, sublinhe-se, na parte final do documento o enfoque é claramente colocado no ensino normal - na formação, pois, de professores. A este respeito, é particularmente interessante a descrição que Boaventura Garção faz da forma como, na Escola Normal Superior de Berna e no âmbito da cadeira de metodologia, os alunos-mestres são iniciados na prática de ensino.

Não obstante as intenções do pensionista português, é certo que o documento que agora publicamos não teve o impacto desejado: o de contribuir para a melhoria da educação em Portugal. Com efeito, tanto quanto julgamos saber, nunca terá sido objeto de qualquer difusão. Mas, mais importante do que essa circunstância, talvez seja o facto de Boaventura Garção, regressado a Portugal no segundo semestre de 1911, ter desempenhado um papel relevante no mundo da educação. Na verdade, em julho de 1912, era professor interino na Escola Normal Feminina de Lisboa ${ }^{6}$. A sua preparação cultural e experiência extrafronteiras - para além de ter concluído o curso normal da Escola de Berna, frequentou, na universidade dessa mesma cidade, uma cadeira de psicologia - investiram-no de um saber que mobilizou certamente na formação das normalistas. Nesse sentido, foi um ator de mudança.

Deixemos, finalmente, ao leitor a possibilidade de interpretar o documento, tendo em devida conta, tanto quanto seja possível, a advertência de Dominick LaCapra (1996): "Rarely do historians see significant texts as important events in their own right that pose complex problems in interpretation and have intricate relations to other events and to various pertinent contexts" (p. 38).

${ }^{6}$ Cf. Diário do Governo, n. 162, de 12/07/1912.

\begin{tabular}{l|l} 
Hist. Educ. [Online] & Porto Alegre
\end{tabular}

v. 17

n. 41

Set./dez. 2013

p. $235-249$ 


\section{Referências}

FERNANDES, Rogério. João de Barros: educador republicano. Lisboa: Livros Horizonte, 1971.

FÜCHS, Eckhardt. Networks and the history of education. Paedagogica Historica, n. 43, 2007, p. 185-197.

IAN/TT. Ministério da Instrução Pública. Cx. 82, Proc. 16.

LACAPRA, Dominick. History \& criticism. Ithaca: Cornell University, 1996.

MIGNOT, Ana Chrystina Venancio; GONDRA, José Gonçalves. Viagens de educadores e circulação de modelos pedagógicos. In: MIGNOT, Ana Chrystina Venancio; GONDRA, José Gonçalves (orgs.). Viagens pedagógicas. São Paulo: Cortez, 2007, p. 7-14.

MORENO-MARTíNEZ, Pedro L. Por las escuelas de Europa: los viajes de Félix Martí Alpera (1900-1911). In: MIGNOT, Ana Chrystina Venancio; GONDRA, José Gonçalves (orgs.). Viagens pedagógicas. São Paulo: Cortez, 2007, p. 114-162.

PINTASSILGO, Joaquim. Imagens e leituras da educação nova em Portugal: os relatórios de bolseiros portugueses em visita a instituições educativas europeias (1907-1909). In: MIGNOT, Ana Chrystina Venancio; GONDRA, José Gonçalves (orgs.). Viagens pedagógicas. São Paulo: Cortez, 2007, p. 195-216.

CARLOS MANIQUE DA SILVA é diretor do Centro de Formação da Associação de Escolas Rómulo de Carvalho e membro da Unidade de Investigação e Desenvolvimento em Educação e Formação, do Instituto de Educação da Universidade de Lisboa. Foi professor visitante nas universidades estaduais de São Paulo e de Santa Catarina, no Brasil. As suas áreas de investigação estão direcionadas para a circulação e difusão do conhecimento pedagógico, a escola graduada e a arquitetura escolar.

Endereço: Rua Casal do Carantão, 10 - 2655-430 - Ericeira - Portugal.

E-mail: manique@net.sapo.pt.

Recebido em 24 de julho de 2013.

Aceito em 22 de agosto de 2013. 


\section{NOTÍCIA SUMÁRIA SOBRE AS INSTITUIÇÕES ESCOLARES DA SUÍÇA, BERNA, JUNHO DE 1911}

A Suíça não tem ministério da instrução pública. As questões relativas à instrução e educação nacional que sejam da competência da Confederação dependem em parte do Departamento Federal do Interior e em parte do Departamento do Comércio, da Indústria e da Agricultura. O Departamento militar ocupa-se da organização dos exames dos recrutas sobre $[\mathrm{sic}]$ o ponto de vista intelectual e sanitário e o Departamento dos Correios e Telégrafos e Caminhos de Ferro ocupa-se das escolas do Gothard e das escolas dos empregados dos caminhos de ferro. O Departamento da Justiça e Polícia ocupa-se também das questões sobre a proteção da infância.

É só a isto que se limita o momento de atividade do poder central no domínio educativo.

A parte principal da instrução pública na Suíça depende dos Cantões. Um certo número de princípios relativos à instrução são postos sobre[sic] a salvaguarda da Confederação, artigo 27 da Constituição federal de 1874, mas de fato a organização e vigilância da instrução pública em todos os graus é do domínio exclusivo dos Cantões. A Suíça não tem, como os grandes países que a cercam, aquela unidade de vistas, aquela uniformidade nas legislações que permite ao estudar-se uma lei, um decreto, uma instrução ministerial, ficar-se orientado sobre o que se passa em todo o território. As [p. 2] instituições escolares suíças oferecem as mais variadas confusões. São tão diversas como as fases sucessivas da sua história, da sua situação geográfica e económica. A Suíça possui tantas legislações escolares como cantões e mesmo meios-cantões. Apressemo-nos de ajuntar que esta uniformidade, convocada por algumas pessoas e considerada como fim escolar a atingir, não é nem útil nem desejável. Em toda a parte o fim é o mesmo. A Suíça varia os meios de o atingir o que é um bem. Cada uma destas pequeninas repúblicas procura a solução dos problemas numerosos, complexos e delicados da educação, nos limites das suas forças e segundo os interesses particulares de cada uma. Resulta daí uma tal emulação entre os Cantões que em nenhuma parte do país existe estagnação, paralisação de esforços, antes pelo contrário, vida, ação, busca incessante no domínio da instrução pública sobre todos os graus de ensino. Nenhum Cantão possui o monopólio do progresso. Basileia foi o primeiro a introduzir os trabalhos manuais nas escolas do sexo masculino. Zurique criou a primeira colónia de férias. A Suíça francesa está ainda hoje em grande avanço sobre a Suiça alemã no que respeita à educação da primeira infância, à organização das escolas infantis, à gratuitidade do material de ensino e ao desdobramento de classes. Mas em compensação a escola complementar foi criada pela primeira vez em Soleure/[p. 3] e foi considerada pelos habitantes da Suíça alemã como o seguimento necessário à escola primária. Foi dos 
Cantões de St. Gallen e de Grisons que partiu o movimento que opôs o sistema educativo de Herbart-Ziller e Stoy ao ensino rotineiro.

A Suíça conta aproximadamente 1100 classes infantis reunindo 4800 crianças. A maior parte destas escolas são organizadas segundo os princípios froebelianos; outras não são mais que simples guardarias ou salas de asilo.

Passando às escolas primárias, encontramos que das 13095 classes 7368 são mistas, 1625 classes para o sexo masculino e 1632 para o feminino 7 ; o princípio de obrigação é bastante diversamente aplicado. Nuns cantões a escola é obrigatória a partir dos 6 anos completos, noutros a partir dos 7 anos somente. $O$ tempo de escola é ainda mais variado. A escola primária dura 6, 7, 8 e mesmo 9 anos segundo os cantões. 0 número total de alunos que frequentam a escola primária é de mais de meio milhão (521383, sendo 260972 sexo masc. e 261411 sexo fem. ${ }^{8}$ ) em aumento de ano a ano. 0 número de professores e professoras que ministram o ensino é de 11777. Existem menos professoras que professores. A média de alunos reunidos numa classe é de 44. Múltiplas e variadas são as disposições respeitantes à frequentação.

É difícil de estabelecer regras uniformes para o ensino secundário suíço. Existe em primeiro lugar o ensino secundário ou o ensino primário superior que os alemães/[p. 4] designam pelo termo gchobem[?] Volksschule. Este ensino reveste os tipos mais diversos segundo os cantões; escolas secundárias propriamente ditas como em Zurique, Thurgovie, Berna, Neuchatel, etc.; escolas de distrito como em Argóvia; escolas regionais como em Friburgo; colégios comunais como no Cantão de Vaud.

O ensino nestas escolas é a continuação natural da escola primária e comporta um total de 1743 classes (1955 mistas, 407 sexo masc. e 381 sexo fem. ${ }^{9}$ ) com 1623 professores secundários e 388 professoras secundárias.

Passemos à escola complementar. Sobre esta denominação são compreendidas as instituições diversas nas quais numas se forma, ao sexo masculino ou ao sexo feminino, ocasião de completar a sua instrução geral ou profissional, em outras tem-se por fim o fazer de novo o programa primário em vista à preparação ao exames de recrutas. Estão classificadas em três categorias: 1 . $^{\mathrm{a}}$, as escolas destinadas a preencher as lacunas de um ensino primário insuficiente; $2 .^{a}$ as escolas destinadas a completar a cultura geral, com ou sem tendências profissionais; $3 .^{a}$ as escolas tendo por fim ministrar a educação profissional necessárias às populações industriais agrícolas e comerciais. No primeiro grupo figuram as escolas às quais se pode chamar de repetição, os cursos complementares de toda a espécie destinados a fornecer aos mancebos conhecimentos indispensáveis para se apresentarem aos exames de/[p. 5] recrutas. O segundo grupo compreende as verdadeiras escolas complementares (Fortbildungsschulen), escolas de aperfeiçoamento como são designadas na Alemanha. Contam-se na Suíça 2470 escolas complementares obrigatórias, frequentadas por 38216 alunos, 237 escolas complementares facultativas, pois que os cursos preparatórios aos exames de recrutas são frequentados por 9000 mancebos.

\footnotetext{
${ }^{7}$ Desdobrando o número de classes pelas categorias indicadas, verifica-se que o autor cometeu um erro de cálculo.

${ }^{8}$ A soma do número de alunos do sexo masculino e do sexo feminino perfaz um total de 522383 alunos e não o número que o autor indicou (521383).

${ }^{9}$ Estamos perante novo erro de cálculo.

\begin{tabular}{l|l} 
Hist. Educ. [Online] & Porto Alegre
\end{tabular}

v. 17

n. 41

Set./dez. 2013

p. $235-249$
} 
Com as medidas referentes a estes exames, provoca-se uma grande emulação entre os Cantões, dando em resultado grandes progressos na instrução suíça. Pode afirmar-se que já não existem analfabetos. Há alguns anos que os recrutas são também examinados sobre o ponto de vista do salto, halteres e carreira.

A formação do pessoal de ensino é feita em 42 instituições especiais: Escolas normais, secções pedagógicas, institutos diversos. 10 destes estabelecimentos são de iniciativa particular. Contam estas escolas uma média de 2198 alunos-professores, sendo 1447 do sexo masculino e 751 do sexo feminino.

Recentemente tem-se organizado cursos de férias, pelas associações pedagógicas, para professores e professoras primários e secundários. Estes cursos são subvencionados pelos cantões.

O ensino secundário, tanto clássico como industrial, comercial e profissional sem ou com relação ao ensino superior, conta 23500 alunos. A duração dos cursos /[p. 6] nos estabelecimentos secundários propriamente ditos varia segundo da(sic) idade de entrada. O termo final é em geral o momento em que os alunos terminam os 18 anos e se apresentam aos exames da maturidade.

O ensino profissional masculino e feminino reveste também as formas mais variadas. Assim as numerosas escolas complementares com tendência profissional como as de Lucerna, de Soleure, Genebra, o ensino ménagère [é] representado por 418 escolas ou cursos e 10547 alunos.

Vem em seguida o ensino profissional propriamente dito nas escolas de artes e ofícios, ou técnicas. A mais antiga é a escola de Winterthur fundada em 1874; Bienne 1890, Berthoud 1892, Friburgo 1896, Genebra 1901, Le Locle 1902.

Acrescentem-se ainda as numerosas escolas de artes e ofícios de desenho, de belas-artes diversamente chamadas segundo os cantões, as escolas de obreiros (Handwerkerschulen, Lehrwerkstätten), escolas de mecânica, de relojoaria, de eletrotecnia e pequena mecânica, de tecidos, de rendas, de escultura.

O ensino comercial, masculino e feminino, tem progredido consideravelmente. Separou-se do ensino industrial e real para tomar o caráter de um ensino puramente profissional. Manifesta mesmo veleidades de se ligar, por algumas das suas disciplinas, ao ensino superior. O ensino comercial é representado por um ensino comercial inferior /[p. 7] nas escolas de comércio propriamente ditas e os Vorkurse e por um ensino comercial superior nas escolas superiores de comércio (Neuchatel, Genebra, Lausane, Friburgo), academias de comunas (Handelsakademie) de St. Gallen, escolas de administração e caminhos-de-ferro.

A Sociedade suíça de comerciantes (Schweiz Kaufmännischer Verun) tem por seu turno feito progredir os estudos comerciais. Os cantões gastam mais de 500000 francos e a Confederação 1800000 fr. anualmente para este ensino complementar comercial. Há ainda os cursos de férias de expansão comercial inaugurados em Lausanne.

Se na agricultura há falta de braços, as escolas agrícolas por esse motivo não faltam: escolas permanentes com domínios juntos para os exercícios práticos: Strickhof, Zurique, escola de viticultura de Wädeusveil, escola Rutti próxima de Berna, Cernier (Neuchatel), Écône (Valais), Escola de Chateleine (Genebra), Escola queijeira (Mondon) etc. 
Não é possível mencionar aqui todas as instituições que dão à mulher uma preparação profissional em vista dos diversos trabalhos que a esperam mais tarde na vida prática: escolas ménagères (Haushaltungsschulen) propriamente ditas, escolas de costura, de corte ou confeção, de rouparia, de criadas (Dienstbotensschulen). Zurique conta mais de 700 alunas nas escolas profissionais femininas, Berna 850, Basileia 1312, Friburgo 227. A Confederação subvenciona/[p. 8] largamente o ensino profissional: 1200 000 francos com o ensino profissional masculino, 400000 fr. com o feminino; com o ensino agrícola e a viticultura 300000 fr. e com o ensino comercial $700000 \mathrm{fr}$.

O ensino superior é representado pelas universidades de Basileia, Berna, Zurique, Genebra, Lausanne, Friburgo e Neuchatel. As duas últimas não têm faculdade de medicina. Trabalha-se para que a Confederação dê subsídios às universidades existentes. A Suíça possui enfim na Escola Politécnica federal em Zurique um estabelecimento científico de primeira ordem. As despesas que se elevam a 1400000 francos são cobertas por inteiro pela Confederação.

A esta lista já longa se vem ainda juntar uma série de estabelecimentos devidos à iniciativa particular e dos quais alguns são hoje do domínio público: asilos diversos, orfanatos, institutos para surdos-mudos, escolas e classes de anormais.

Para terminar esta rápida vista através das leis e instituições escolares suíças, diremos enfim que os exames de recrutas são organizados à custa da Confederação que dá subsídios igualmente para o ensino da ginástica e exercícios militares preparatórias; para seis exposições escolares permanentes de Zurique, Berna, Friburgo, Lausanne, Neuchatel e Lucerna; para as duas Comissões encarregadas da escolha dos livros para uso da juventude e para as bibliotecas; para quaisquer outras obras/[p. 9] científicas de interesse geral: Exposições e congressos na Suíça e Estrangeiro, Sociedade helvética de ciências naturais, Comissão geodésica, Comissão geológica, Sociedade de história nacional, Dicionário dos dialetos da Suíça alemã, Dicionário dos dialetos da Suíça francesa, Sociedade suíça de estatística, Bibliografia suíça, Sociedade de professores de ginástica, Sociedade de músicos suíços, Sociedade suíça de tradições populares, Progresso das Belas-Artes, Conservação de antiguidades nacionais (Museu nacional suíço), Anuários de instrução pública e quaisquer outras publicações.

Resumindo tudo o que precede encontramos nos orçamentos cantonais e comunais as somas seguintes: Escolas primárias 50000000 fr.; escolas secundárias 7200000 fr.; escolas complementares e profissionais 6400000 fr.; ensino secundário superior, incluindo escolas normais $6000000 \mathrm{fr}$.; ensino superior $4800000 \mathrm{fr}$.

A Confederação dá por seu turno para subsídios diversos 6100000 fr.

A Suíça gasta com uma população de 3500000 habitantes a soma de 80500000 francos para as suas instituições escolares públicas.

/[p. 10] Organização escolar no Cantão de Berna

Jardins e escolas infantis. Estes estabelecimentos não são ainda organizados pelo Estado. Deixa-se esse cuidado às comunas e à iniciativa particular. A idade de entrada para estas escolas vai desde $2 \frac{1}{2}$ anos até aos 5 anos. O ano letivo compreende 24 a 48 semanas, começando na primavera. Algumas destas escolas são gratuitas, mas na maioria delas é necessário pagar matrícula. 
Escola primária obrigatória. A idade mínima de admissão é de 6 anos feitos até 1 de janeiro. Todas as crianças que atinjam esta idade até 1 de janeiro são obrigadas a frequentar a escola primária desde o princípio do ano letivo seguinte que começa em abril. Todas as crianças que atingirem os 6 anos até 1 de abril são também admitidas a frequentar a escola primária se os pais assim o desejarem. As crianças que completarem os 6 anos depois deste tempo esperam até ao ano letivo seguinte. As crianças em idade escolar que não são suficientemente desenvolvidas corporal ou intelectualmente aguardam até ao ano letivo seguinte a pedido dos pais ou por decisão da comissão escolar.

A duração da escolaridade vai até aos 15 anos, em certos casos até aos 14 . O primeiro grau compreende os alunos de 6 a 9 anos (I-III anos escolares); /[p. 11] o segundo grau compreende os alunos de 9 a 12 anos (IV-VI anos escolares); o terceiro grau alunos de 12 a 15 anos, algumas vezes 14 anos, ou seja os anos escolares VII, VIII e IX. O ano letivo principia no dia 1 de abril. As escolas funcionam pelo menos 34 semanas em cada ano letivo nas comunas onde o tempo de escola é de 9 anos; e 40 semanas pelo menos onde o tempo de escola dura 8 anos.

Em regra a escola deve ser frequentada durante 9 anos, as comunas entretanto têm direito de poder reduzir a duração a 8 anos (Gesetz über der Primarunterricht § 59). Esta lei é só introduzida em 46 comunas todas do Jura. As outras 532 comunas do Cantão de Berna são obrigadas à frequência durante 9 anos.

Duração da frequência nos 9 anos:

a) Primeiro grau. Anos escolares I-III. 800 horas de lições em cada ano pelo menos.

b) Segundo grau. Anos escolares IV-VI. 900 horas de lições em cada ano.

c) Terceiro grau. Anos escolares VII-IX. 900 horas de lições em cada ano pelo menos.

Duração da frequência nos 8 anos:

a) Primeiro grau. Anos escolares I-Il: mínimo 800 horas. III ano escolar: mínimo 1100 horas de lições.

b) Segundo grau. Anos escolares IV-VI. Mínimo 1100 horas de lições por ano.

c) Terceiro grau VII ano escolar 1100 horas de lições. VIII ano escolar. Mínimo 900 horas de lições por ano./[p. 12]

Nestes números são incluídas as lições de trabalhos de agulha e de ginástica. $O$ número de horas de lições semanais não vai além de 26 nos três primeiros anos e 33 nos outros. Não se dão mais de 5 horas de lições por dia durante os três primeiros anos, e mais de 6 horas de lições nos outros anos. O número de horas hebdomadárias pode ser diminuído onde o ensino é feito por secções. Uma classe que compreenda os três graus (são raras) não deve contar mais de 60 alunos, e uma classe que compreenda só um ou dois graus não conta mais de 70 alunos. Se o máximo de alunos vai além destes números durante três anos consecutivos, a comuna é obrigada a fazer ministrar o ensino por secções ou cria uma nova classe.

Mas ordinariamente em quase todas as comunas existem escolas centrais, onde para cada ano escolar há um professor, formando-se sempre classes paralelas de cada ano escolar quando o número de alunos de qualquer for além do prescrito. Nas comunas cuja população escolar é menos importante, o ensino é ministrado de forma que cada 2 ou 3 anos escolares tenha um professor. Nalgumas pequenas freguesias existem apenas 
2 professores e só nos lugarejos pouco populosos existe um professor para todos os 9 anos escolares.

O ensino nas classes elementares é ministrado em regra por professoras.

A escola primária compreende classes mistas, onde as crianças dos dois sexos recebem o ensino em comum, mas onde as condições particulares assim o exigirem,/[p. 13] as comunas podem desdobrar as classes por sexo com autorização da Direção da Instrução Pública.

Nas comunas onde o ensino obrigatório é de 9 anos as crianças podem sair da escola já ao fim do $8^{\circ}$ ano escolar, se por meio de um exame se verificar que essas crianças percorreram o ciclo de estudos da escola primária.

Nas comunas onde o ensino é de 8 anos, as alunas são obrigadas a frequentar durante ainda um ano a escola de lavores ou uma escola complementar para o sexo feminino se nestas comunas as houver.

Estão em uso as excursões escolares especialmente no semestre de verão. A aprendizagem da natação é obrigatória para os dois sexos. Os trabalhos manuais têm sido introduzidos em muitas comunas. A música é ensinada em todas as escolas bem como a ginástica.

Ao lado das classes do grau superior de instrução primária as comunas são autorizadas a criar classes primárias superiores compreendendo pelo menos 36 semanas com 24 a 33 lições. Estas classes abrangem os três últimos anos escolares; excecionalmente elas podem abranger um ano mais. O número de matérias de ensino nestas classes é superior aos das outras classes primárias, pois que juntam nelas grandes traços de geografia e de história geral, ciências naturais e francês para as escolas alemãs, e alemão para as escolas francesas do Jura.

Os alunos com capacidade para frequentar o grau/[p. 14] superior de uma comuna que não tenha escola secundária, nem escola superior, são autorizados a seguir as lições da escola primária superior da comuna mais próxima se se comprometerem a seguir um curso de 3 anos. As despesas correm por conta da comuna a que esses alunos pertencem.

As comunas podem declarar obrigatório o ensino da ginástica para as crianças do sexo feminino, e o ensino dos trabalhos manuais para as do sexo masculino. Se os trabalhos manuais ocasionam despesas particulares o Estado também participa nelas por meio de subsídios.

As escolas de lavores compreendem em média 42 a 44 semanas de escola por ano. Os trabalhos de agulha são obrigatórios para todas as alunas da escola primária. As alunas do grau superior que tenham adquirido conhecimentos suficientes neste ramo de ensino podem ser dispensadas dele pela comissão escolar, depois de um exame no começo de um ano letivo. O número de lições hebdomadárias é de 4 a 6 no verão e 3 a 4 no inverno repartidas em dois meios dias. No inverso se as lições não duram mais de uma hora podem seguir-se às outras lições, sobretudo no grau inferior.

As crianças fracas de espírito (Schwachsinnige) formam classes à parte.

Podemos ainda citar a exposição escolar permanente de Berna, como estabelecimento auxiliar da escola primária. 
/[p. 15] Escola complementar (Fortbildungsshulen).

A escolar complementar é destinada aos mancebos que acabaram de frequentar a escola pública propriamente dita mas que não atingiram ainda a idade do serviço militar. É nestes limites que as comunas fixam a idade de admissão às escolas complementares. As comunas são autorizadas a declarar estas escolas obrigatórias; algumas comunas reúnem-se para criarem uma escola em comum.

O Estado contribui com a metade dos ordenados dos professores complementares. Quando uma comuna cria uma escola complementar, esta é obrigatória para todos os mancebos domiciliados no território da comuna e que estejam na idade fixada pelas autoridades; só são dispensados os mancebos que a este tempo estão frequentando um estabelecimento de instrução superior ou uma escola complementar profissional.

Qualquer aluno de uma escola complementar pode deixar de a frequentar desde o momento que prove num exame que possui conhecimentos suficientes nas matérias obrigatórias.

O ensino nestas escolas compreende dois cursos anuais contando pelo menos 60 horas de lições; na maior parte começam em outubro ou novembro. A idade de admissão é de 15 a 18 anos. Os cursos obrigatórios são gratuitos. Ao lado das escolas obrigatórias há outras que são facultativas.

/[p. 16] As comunas que organizam escolas complementares para o sexo feminino, assim como escolas ménagères (Haushaltungsschulen) ou cursos do governo da casa (Haushaltungskurse) são subvencionadas pelo Estado, quando a organização dessas escolas corresponde bem ao fim em vista.

O regulamento das escolas complementares de 14 de novembro de 1894 em vigor, cita como sendo matérias obrigatórias: língua maternal e contabilidade, aritmética e geometria prática, história suíça, geografia, instrução cívica e geografia geral, ensino profissional, sobretudo agrícola e industrial segundo as localidades.

Há no Cantão de Berna escolas complementares obrigatórias em 560 localidades com 865 professores e 8959 alunos em média. Estes números têm em vista aumentarem como se vê no Jahrbuch des Unterrichtswesens in der Schweiz.

A escola complementar profissional é obrigatória em 46 comunas.

Cursos preparatórios para recrutas. Estes cursos não são organizados por lei. A frequentação deles é facultativa. A idade de admissão é a idade ao serviço militar. Estes cursos compreendem em geral 40 horas de lições, repartidas em 20 dias durante 10 semanas, e são ministrados durante o inverno que precede o recrutamento. Depois da entrada em vigor da lei de instrução primária/[p. 17] de 1894 que autoriza as comunas a declarar obrigatória a escola complementar, o número destes cursos diminuiu sensivelmente, precisamente devido à criação de um grande número destas escolas.

Escolas secundárias inferiores (Sekundarschulen).

As 93 escolas secundárias do Cantão de Berna dividem-se em: a) Escolas reais nas quais as matérias literárias não são obrigatórias; b) Proginásios nos quais estas matérias são ensinadas ao mesmo tempo que as ciências. A frequência é facultativa e depende de um exame de admissão. A idade mínima é 10 anos completos. Estas escolas compreendem 2-5 classes; o ano letivo é de 42-44 semanas; número máximo de lições é de 33. Contribuição escolar vai de 10 a 60 francos por ano. $O$ ensino de trabalhos de 
agulha para o sexo feminino é regido pelas mesmas disposições da escola primária. Mas nas escolas secundárias só para o sexo feminino existe um plano de estudos especial para os trabalhos de agulha.

Escolas secundárias superiores (Mittelschulen)

A sua organização deriva da lei de 1856 das escolas secundárias e da de 1877 que suprime as escolas cantonais. As escolas secundárias e os ginásios são uma espécie de instituição intermédia entre as escolas comunais e os estabelecimentos cantonais. As comunas fundam estas escolas e asseguram a sua garantia durante 6 anos; $O$ Estado reconhece-as se elas satisfazem todas as condições/[p. 18] legais e contribui com um subsídio para pagamento de metade do total dos ordenados; não contribui para outras despesas. Há contudo um certo número de escolas secundárias que recebem um subsídio extraordinário de 200 até 1000 francos. As contas anuais determinadas pelas comissões escolares devem ser aprovadas pela Direção de instrução pública.

Escola secundária para o sexo feminino de Berna (Städtische Mädchensekundarschule Bern): compreende uma escola secundária propriamente dita e uma divisão superior que abrange: a) Uma escola normal do sexo feminino. Idade de admissão, 15 anos. b) Uma escola de comércio. c) Curso de aperfeiçoamento.

As outras secundárias superiores são as seguintes:

Escola secundária para o sexo feminino de Bienne.

Ginásio de Berthoud com $8 \frac{1}{2}$ de estudos.

Escola cantonal de Porrentruy. 8 1/2 de estudos.

Ginásio livre de Berne para o sexo masculino.

Proginásio de Thoune. Proginásio de Neuveville.

Proginásio de Delemount. Ginásio municipal de Berna. Escola de comércio de St. Irnier.

A idade de admissão em quase todas estas escolas é a idade de 10 anos, quase todas preparam à maturidade.

\section{Escolas normais}

A lei sobre as escolas normais do Cantão de Berna de 18 de julho de 1875 diz no seu primeiro artigo: 4 a 6 escolas normais servem para formar o pessoal/[p. 19] ensinante das escolas primárias públicas. Os alunos recebem nas escolas normais não somente a instrução necessária mas também alojamento e alimentação onde as circunstâncias o tornarem desejável. Os alunos devem ser iniciados na arte de reger uma escola e fazer os seus exercícios práticos nas classes das escolas primárias de aplicação. Os estudos nas escolas normais para professores são 4 anos e para professoras de 3 anos. Férias anuais 10 semanas. $O$ ano letivo principia em maio.

1. ' Escola normal alemã d' Hofrvil e Berna. Esta escola foi dividida, por decisão do Grande Conselho de 19 de fevereiro de 1903, em Escola normal inferior de Hofrvil e Escola normal superior de Berna. Compreende 4 anos de estudos; os dois primeiros na escola inferior de Hofrvil, e os dois últimos na escola superior de Berna. Os alunos da primeira têm internato na escola, os da Escola normal superior não têm internato mas recebem uma pensão mensal de 50 francos e são alojados em casa de boas famílias indicadas pelo Diretor da Escola. Para serem admitidos à frequência da Escola Normal os 
candidatos fazem um exame de admissão. A Escola Normal de Berma recruta os alunos saídos das escolas secundárias inferiores ou das classes correspondentes dos ginásios. Idade de entrada é de 15 anos completos. Na secção profissional da Escola Normal superior de Berna os alunos recebem ensino de psicologia experimental durante dois anos/[p. 20] e pedagogia durante um ano. Este ensino é feito pelo Diretor da Escola. Na cadeira de metodologia o professor acompanha os alunos à prática nas escolas. Todos os oito dias um aluno tem uma lição prática na presença de toda a classe da escola normal e em seguida reúne-se a mesma classe em conferência debaixo da presidência do professor de métodos. Nesta conferência faz-se a crítica do modo como o aluno deu escola e discute-se qual seria a melhor maneira de fazer o ensino. Os alunos são obrigados a fazerem as suas preparações num caderno especial, mostram essas preparações aos professores das classes da escola de aplicação e só depois destes terem feito as correções necessárias, os alunos podem começar as lições práticas. 0 ensino em todas as matérias, exceto na leitura, é feito sem livro, todos os alunos portanto são obrigados a prepararem-se conscienciosamente em casa. Na Escola normal de Berna o ensino de música é tomado em muita consideração. Duas lições semanais de teoria e canto. Uma lição por semana de coro a quatro vozes. Todos os alunos são obrigados a aprender um instrumento: piano, órgão ou violino.

2. ${ }^{a}$ Escola normal alemã para professores de Hindelbank. É um estabelecimento oficial que recebe alunos de 16 anos de idade. A duração dos estudos é de 3 anos e as lições são dadas durante 42 semanas em cada ano. O ensino é gratuito. Existe inter/[p. 21] nato onde os alunos pagam uma diminuta pensão segundo a fortuna dos pais.

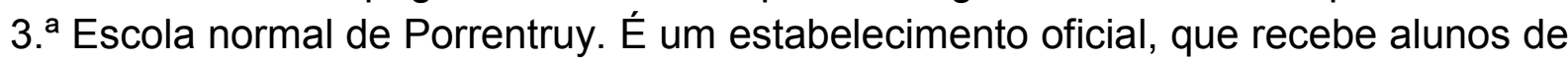
idade de 15 anos. O curso é de 4 anos e o ano letivo é de 42 semanas.

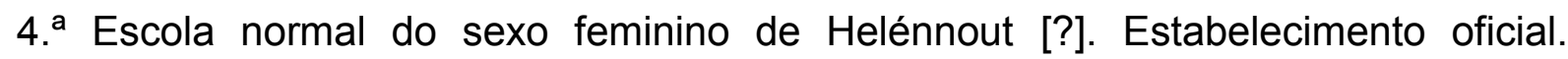
Admissão: 15 anos.

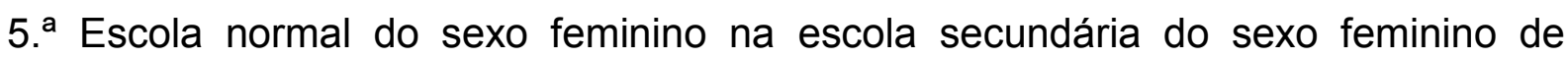
Berna. Idade de entrada 15 anos, 3 anos de estudos e 42 semanas por ano. Nestas escolas paga-se uma matrícula de 30 francos por semestre.

6. ${ }^{a}$ Escola normal evangélica de professores de Muristalden, Berna. É um estabelecimento particular. Idade de admissão é de 15 anos. O curso dura 4 anos.

7. ${ }^{a}$ Escola normal do sexo feminino na nova Escola secundária do sexo feminino de Berna. É igualmente um estabelecimento particular. As alunas são admitidas aos 15 anos de idades. O curso dura 3 anos.

8. ${ }^{a}$ Escola normal para professores e professoras secundários. Faz parte integrante da Universidade de Berna e mais particularmente da Faculdade de Filosofia.

Estabelecimentos profissionais

Entre os numerosos estabelecimentos profissionais pertencentes ao Estado, às comunas, às corporações e aos particula/[p. 22] res, citaremos apenas as duas escolas técnicas de instrução profissional superior: Thecnicum cantonal de Berthoud e o Technicum cantonal de Bienne.

O Cantão possui ainda uma Universidade em Berna com 6 faculdades: Faculdade de teologia evangélica, faculdade de teologia católica, faculdade de Direito, de medicina, de veterinária e de filosofia. 
O Cantão de Berna com uma população de 645000 habitantes gastou em 1910 com a instrução:

Escolas primárias

2.684 .738 fr. e 75 cêntimos

Escolas secundárias inferiores e superiores 1.173 .539 fr. e 95

Escolas superiores e escolas veterinárias 986.462 fr. e 23

Escolas normais 255.558 fr. e 95

Escolas de surdos-mudos $90.871 \mathrm{fr}$.

Escolas de Belas-artes e desenho $51.607 \mathrm{fr}$.

Administração da Direção e Sínodo Escolar 44.087 fr. e 75 cêntimos

Total 5.286 .865 francos e 63 cêntimos 